\title{
A substituted pyrrolidinone, BMY 21502, and classical conditioning of the nictitating membrane response in young and older rabbits
}

\author{
DIANA S. WOODRUFF-PAK, JOAN M. COFFIN, and MICHELLE PAPKA \\ Temple University, Philadelphia, Pennsylvania
}

\begin{abstract}
New Zealand white rabbits ( $N=76$; 38 at 3 months, 38 at $21-55$ months) were classically conditioned for 1090 -trial sessions in the 750 -msec delay paradigm using a tone conditioned stimulus (CS) and corneal airpuff unconditioned stimulus (US). Young and older rabbits were divided into groups receiving paired CS-US presentations with 0,5 , or $10 \mathrm{mg} / \mathrm{kg}$ of BMY 21502 . Unpaired tone and airpuff presentations were given to control groups administered 0 or $5 \mathrm{mg} / \mathrm{kg}$ of BMY 21502 . Over training sessions, the older BMY-21502-treated rabbits produced a higher percentage of conditioned responses (CRs) and greater CR amplitude than did the vehicle-treated older rabbits. BMY 21502 did not facilitate conditioning in the young rabbits. There were significant age differences in acquisition between the young and older vehicle-treated animals. Although the BMY-21502-treated older rabbits did not achieve the asymptotic level of performance of the young rabbits, BMY 21502 treatment resulted in conditioning for the older rabbits that was similar to that for the younger rabbits.
\end{abstract}

Classical conditioning of the nictitating membrane (NM)/eyeblink response in rabbits is promising as a model system for the study of learning, memory, and aging. This model system provides a behavioral paradigm in animals that has a close analog in human behavior and thus has potential utility in behavioral pharmacology (Harvey \& Gormezano, 1986; Schindler, Gormezano, \& Harvey, 1984; Woodruff-Pak, 1990; Woodruff-Pak, Coffin, \& Sasse, 1991). For this simple kind of learning to occur, a neutral stimulus such as a tone or a light conditioned stimulus (CS) is presented first, followed about half a second later by a corneal airpuff unconditioned stimulus (US). The US always causes the organism to blink, thus producing an unconditioned response (UR). The repeated pairing of the CS and US results in a conditioned response (CR): the organism blinks to the CS before the onset of the US. The NM response and the eyeblink response in the same eye of the rabbit are highly correlated $(r=.99)$ and show similar patterns of response

The authors gratefully acknowledge the advice and encouragement of Sandra Moon and Michael Eison of Bristol-Myers Squibb. David Dalton of the Temple University Chemistry Department provided invaluable suggestions. Harry Riley combined the compounds and created the code to keep investigators blind to dosage level. Doris Sasse and Melissa Haunton contributed to this research, especially in training the rabbits. Guerda Almonor, Crystal Bellinger, and John Smith assisted with the rabbit training. Some of these data were presented at the "Zurich VI" meeting (of the International Study Group on the Pharmacology of Memory Disorders Associated with Aging, and included in the proceedings) and are included in the 1991 Society for Neuroscience Abstracts. Address correspondence to D. S. Woodruff-Pak, Department of Psychology, Temple University, Philadelphia, PA 19122 (e-mail: kioku@vm.temple.edu). during classical conditioning (McCormick, Lavond, \& Thompson, 1982).

Understanding of the neurobiological circuitry for classical conditioning of the NM/eyeblink response in the rabbit has progressed rapidly in the last decade (Thompson, 1986, 1990; Thompson et al., 1976). Evidence to date strongly suggests that there are two major brain structures involved in NM/eyeblink classical conditioning: the hippocampus and the cerebellum. The hippocampus plays a modulatory role in acquisition, and the cerebellum appears to be the site of the plasticity involved in acquiring CRs.

The nootropic compound BMY 21502 was developed for the purpose of improving impaired cognitive functioning in old age, cerebrovascular disease, and dementias such as Alzheimer's disease. Like most nootropic agents, BMY 21502 is a pyrrolidinone derivative. The protypic nootropic piracetam, a substituted pyrrolidinone, is an analog of gamma aminobutyric acid (GABA) and has clear effects on brain metabolism (Giurgia, 1976). Research has demonstrated that similar pharmacophores, including substituted pyrrolidinones such as the acetams, modulate hippocampal synaptic transmission and long-term potentiation (LTP) in vitro (Olpe \& Lynch, 1982; Satoh, Ishihara, Iwama, \& Takagi, 1986).

The demonstrated ability of BMY 21502 to enhance learning and memory and to activate the CA1 hippocampal region of older rats suggested to us that the compound might facilitate acquisition of the conditioned $\mathrm{NM}$ /eyeblink response in older rabbits. When old rats were administered BMY 21502, the predominate pattern of metabolic activity in CA1 resembled the pattern seen in young adult rats (Moon et al., 1988). In young adult rats, BMY 21502 prevented memory disruption at a 
statistically significant level in a step-down passive avoidance task that is normally disrupted by electroconvulsive shock (ECS; Gribkoff et al., 1989). All doses of BMY 21502 in the range of $0.25-10 \mathrm{mg} / \mathrm{kg}$ protected memory in the passive avoidance/ECS paradigm, with higher doses producing less protection. BMY 21502 facilitated acquisition of Morris water task performance in 16- to 18-month-old rats (Linder \& Gribkoff, 1992) and in young rats subjected to traumatic brain injury (Pierce, Smith, Eison, \& McIntosh, 1993). In monkeys, BMY 21502 enhanced acquisition in a shape discrimination task, but it did not improve memory retention in a delayed matching-to-sample procedure (Fitten, Perryman, Hanna, \& Menon, 1990).

Gribkoff and associates (1989) also reported that intravenous administration of BMY 21502 to young adult rats at various doses up to $1.0 \mathrm{mg} / \mathrm{kg}$ produced no changes in spontaneous activity of neurons of dorsal raphe, locus coeruleus, substantia nigra, ventral tegmentum, or dorsal hippocampus. Whereas spontaneous neural activity in dorsal hippocampus and brain stem was not affected by BMY 21502, LTP of populationevoked synaptic responses in hippocampus were significantly enhanced with the compound. At concentrations of 1.0 and $10 \mu \mathrm{M}$ in slices from young adult and very old rats (2.5-3.2 years), BMY 21502 produced significant enhancement of LTP (Gribkoff, Bauman, \& VanderMaelen, 1990). This significant enhancement was observed in aged rats in assessments made as long as 50 min after the conditioning train of electrical stimuli.

Deficits in the classically conditioned eyeblink response resulting from normal aging have been demonstrated in four species: rabbits, cats, rats, and humans (Braun \& Geiselhart, 1959; Coffin \& Woodruff-Pak, 1991; Graves \& Solomon, 1985; Harrison \& Buchwald, 1983; Kimble \& Pennypacker, 1963; Powell, Buchanan, \& Hernandez, 1981; Solomon, Pomerleau, Bennett, James, \& Morse, 1989; Weiss \& Thompson, 1991; WoodruffPak, Lavond, Logan, \& Thompson, 1987; Woodruff-Pak $\&$ Thompson, 1988). The purpose of the present investigation was to explore the cognition-enhancing properties of BMY 21502 on classical conditioning of the NM/ eyeblink response in young and older rabbits. We tested the hypothesis that BMY 21502 would ameliorate deficits in acquisition in older rabbits and possibly enhance acquisition in young rabbits.

\section{METHOD}

\section{Subjects}

Seventy-six New Zealand, white, specific-pathogen-free (SPF) rabbits -38 young rabbits that were 3 months old and 38 in the age range of 21 to 55 months - were tested. Seventeen of the rabbits were male ( 10 young, 7 older), and 59 were female ( 26 young, 33 older). The male rabbits were divided relatively equally among the treatment groups. Furthermore, there were no sex differences in classical conditioning (e.g., sex differences for trials-to-learning criterion of eight CRs in nine consecutive trials in the 48 rabbits in the paired groups were 474 for females $(N=36)$ and $429(N=$ 12) for males $[t(46)=0.53$; n.s.]. The older rabbits were retired breeder rabbits with a mean age of 32 months. The birthdates of the SPF rabbits were certified by the breeder. The rabbits were kept on a 12:12-h light:dark cycle and were run during the light period of the cycle. It took approximately $6 \mathrm{~h}$ to run $6 \mathrm{rabbits} /$ day, so some of the rabbits were run earlier in the light portion of the cycle than others. However, individual rabbits were consistently run at the same time.

\section{Apparatus}

A Plexiglas Gormezano restrainer, designed for the larger size of older rabbits, was used to restrain each rabbit during classical conditioning. Elastic eyelid retractors held the left eye open. A removable platform to hold the headstage was secured behind the ears and under the animal's muzzle. The headstage attached to this platform held a nozzle positioned $1 \mathrm{~cm}$ from the cornea, through which the airpuff US was presented. Also on the headstage was a minitorque potentiometer (for NM movement measurement). The potentiometer was attached by a lever and a thread to a nylon suture loop in the NM. A computer programmed with FORTH and assembly language and interfaced with the stimulus equipment controlled the presentation and duration of stimulus events, collected analog data, and extracted dependent variable measures of conditioning. A minitorque potentiometer on the headmount converted NM movements into electrical signals that were subjected to an analog-to-digital analysis. The digitized values were analyzed from RAM immediately after each training session and also routinely logged on to a floppy disk for permanent storage.

\section{Procedure}

The 750-msec CS-US interval delay paradigm was chosen because this paradigm is more difficult for young rabbits and especially more difficult for older rabbits than is the delay paradigm at shorter CS-US intervals (e.g., $400 \mathrm{msec}$; Sasse, Coffin, \& WoodruffPak, 1991). Older rabbits, on average, attain a criterion of eight CRs in nine consecutive trials on Day 9 of training (of 90 -trial sessions), although some older rabbits never attain this criterion in 10 sessions. Young rabbits, in contrast, attain learning criterion in the 750-msec CS-US interval delay paradigm in the fourth session on average (Sasse \& Woodruff-Pak, 1990).

The rabbits were placed into restrainers for two adaptation sessions before training or drug injections began. For training, they were injected subcutaneously (s.c.) with drug or vehicle $15 \mathrm{~min}$ before training. Next they were placed into the restrainer, fitted with the headmount, and then positioned in a ventilated and soundattenuated experimental chamber. An $850-\mathrm{msec}, 85-\mathrm{dB}, 1-\mathrm{kHz}$ tone CS was followed $750 \mathrm{msec}$ after its onset by a $100-\mathrm{msec}$, 3-psi corneal airpuff US. The CS and US coterminated. Each daily session was comprised of 90 trials, and all trials were paired CS-US trials. The intertrial interval was random, ranging from $10-20 \mathrm{sec}$. The entire session lasted 35 to $45 \mathrm{~min}$. Training was completed within $1 \mathrm{~h}$ after drug administration, while the compound was likely attaining peak blood levels. For the explicitly unpaired conditioning group, all procedures were the same as those for the paired conditioning sessions, except that the tone and airpuff were not presented together. Each session consisted of $180 \mathrm{ex}-$ plicitly unpaired trials of tone or airpuff presentations. The intertrial interval was random, ranging from 10 to $20 \mathrm{sec}$.

A CR was automatically scored by the computer system if the NM movement exceeded $0.5 \mathrm{~mm}$ and occurred in the period between 25 and $750 \mathrm{msec}$ after onset of the tone CS. The learning criterion was the production of eight CRs in a sequence of 9 consecutive trials. The UR was the reflexive blink to the corneal airpuff and was scored as any response occurring in the interval between 751 and $1,041 \mathrm{msec}$ after CS onset. Amplitude of the CR was measured in millimeters at the point of peak amplitude of the response (between 25 and $750 \mathrm{msec}$ after CS onset). For each trial on which there was no $\mathrm{CR}$, a zero was added to the CR amplitude measure for the session. Thus, mean CR amplitude measures for 
each session represent performance for 90 trials and are lower than they would be if the mean included only CR trials. Amplitude of the UR was measured in millimeters at the point of peak amplitude in the interval after US onset (between 751 and 1,041 msec after CS onset). Response latency was scored as the interval (in milliseconds) after CS onset when an NM response was $0.5 \mathrm{~mm}$ or more in amplitude

Three days after the last testing session, each rabbit was deeply anesthetized with sodium pentobarbital. When it showed no reflexes to strong stimulation, it was decapitated, and the brain was removed and rapidly frozen. Brains were stored at $-80^{\circ}$ for further analyses.

\begin{abstract}
Drug
The rabbits were injected s.c. $15 \mathrm{~min}$ before training with vehicle alone or drug dissolved in vehicle. Compounds were prepared by staff in the biological sciences department in a laboratory located across campus. Solutions were labeled by color name, and the code was kept in a sealed envelope. Animal runners were blind to the nature of the compound. For both the young and older rabbits, there were five conditions-paired tone and airpuff presentations with (1) vehicle alone $(0 \mathrm{mg} / \mathrm{kg}$ of BMY 21502); (2) $5 \mathrm{mg} / \mathrm{kg}$ of BMY 21502 ; (3) $10 \mathrm{mg} / \mathrm{kg}$ of BMY 21502 ; (4) unpaired tone and airpuff presentations with $5 \mathrm{mg} / \mathrm{kg}$ of BMY 21502 ; (5) unpaired tone and airpuff presentations with vehicle $(0 \mathrm{mg} / \mathrm{kg}$ of BMY 21502). There were 6 rabbits in each group treated with BMY 21502, 12 rabbits in each of the young and older paired vehicle groups, and 8 rabbits in each of the young and older unpaired vehicle groups.
\end{abstract}

\section{RESULTS}

A number of dependent measures are available for the analysis of NM classical conditioning data, making it possible to carry out a large number of analyses. Due to the large number of statistical tests, a probability level of .01 was used to reduce the chance of making a Type I error.

\section{Effects of BMY 21502 and Age on Acquisition}

To compare the effects of age and BMY 21502 on acquisition, a $2 \times 3 \times 10$ repeated measures analysis of variance (ANOVA) was carried out to examine the effects of age, treatment dose of BMY 21502 (0 [vehicle], $5,10 \mathrm{mg} / \mathrm{kg}$ ), and training sessions on percentage of CRs. The effect of age was significant $[F(1,42)=11.81, p<$ $.01]$, as was the effect of training sessions $[F(9,378)=$ $27.72, p<.001]$. The effect of treatment dose of BMY 21502 and the interactions did not attain statistical significance. The young rabbits acquired a higher percentage of CRs than the older rabbits, and all the rabbits increased percentage of CRs over training sessions.

Initial data analyses demonstrated that the doses of 5 and $10 \mathrm{mg} / \mathrm{kg}$ of BMY 21502 had virtually identical effects on acquisition. To gain power in subsequent analyses, the data from the rabbits treated with 5 and $10 \mathrm{mg} / \mathrm{kg}$ were collapsed into one BMY 21502 group. The dependent measures of amplitude of the $C R$ and response latency were analyzed in separate $2 \times 2 \times 10$ repeated measures ANOVAs comparing the effects of age, treatment dose of BMY 21502 (drug vs. vehicle), and training sessions.
Amplitude of the CR is a measure of acquisition in the $\mathrm{NM}$ classical conditioning paradigm. At the beginning of training, there is little or no NM response in the CR period, because rabbits do not blink to the tone. As the association between the tone CS and corneal airpuff US occurs, the magnitude (CR amplitude) as well as the percentage of CRs increase. The effect of age was significant, as CR amplitude was significantly greater in the young rabbits $[F(1,44)=10.47, p<.005]$. The effect of training sessions was significant, with $C R$ amplitude increasing significantly in all the rabbits across the 10 training sessions $[F(9,396)=8.76, p<.001]$. Neither the main effect of treatment dose of BMY 21502 nor any of the two-way interactions achieved statistical significance. The age $\times$ treatment $\times$ training sessions interaction was statistically significant $[F(9,396)=2.60$, $p<.01]$.

In order for an NM response to be a CR, it must be at least $0.5 \mathrm{~mm}$ at a latency before the onset of the corneal airpuff US (at $750 \mathrm{msec}$ ). Thus, response latency initially occurs as a UR after the US onset at $750 \mathrm{msec}$ and shortens as CRs are produced. The effect of age on response latency was significant, as the young rabbits responded at shorter latencies $[F(1,38)=13.96, p<.001]$. The effect of training session was also significant, as over the 10 training sessions response latency shortened for all the groups $[F(9,342)=15.32, p<.001]$. The main effect of treatment did not achieve statistical significance with the dependent measure of response latency. The age $\times$ training sessions and the age $\times$ treatment $\times$ training sessions interactions were statistically significant $[F(9.342)=3.04, p<.005$, and $F(9,342)=$ $2.52, p<.005$, respectively; see Figure 1].

An interesting feature of these results is that acquisition for the old rabbits treated with BMY 21502 began to approximate the acquisition of the young rabbits. A

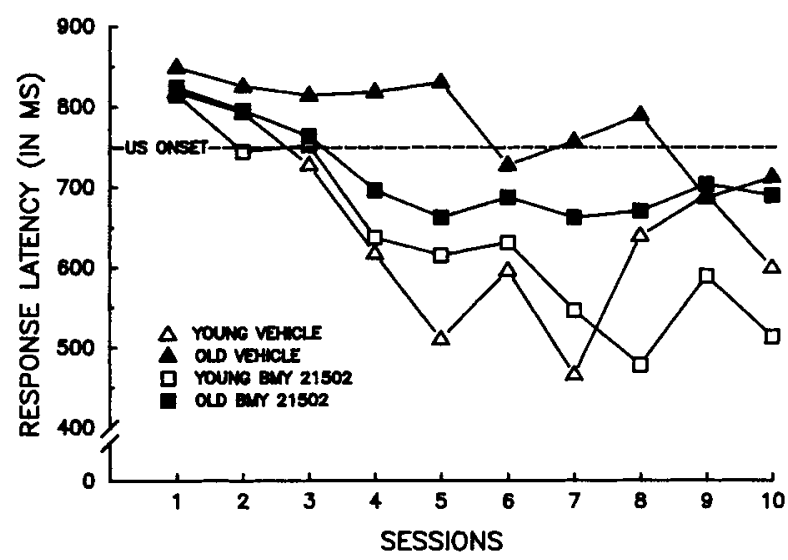

Figure 1. Response latency in young and older rabbits over 10 classical conditioning sessions of 90 paired tone conditioned stimulus (CS) and comeal airpuff unconditioned stimulus (US) presentations. There were two treatment conditions of paired tone CS and airpuff US after subcutaneous administration of vehicle or BMY 21502 (dose of 5 or $10 \mathrm{mg} / \mathrm{kg}$ per day). There were 12 rabbits in each group. 
post hoc Scheffé test comparing the percentage of CRs in the BMY-21502-treated older rabbits with the percentage of CRs in all the young rabbits indicated that the groups were not different. However, the Scheffé test is very conservative in detecting differences. Another way to demonstrate comparable performance in all the young rabbits and the older BMY-21502-treated rabbits is to compare the percentage of CRs in the critical sessions when learning criterion is attained: Sessions 4-6. An ANOVA was carried out to compare the percentage of CRs in all the groups of young rabbits with the percentage of CRs in the BMY-21502-treated older rabbits in Sessions 4-6. Percentage of CRs was not significantly different between the two groups in these sessions $[F(1,34)=$ $2.54, p=0.12$, n.s.].

Asymptotic performance in NM conditioning as assessed by percentage of CRs typically approaches $80 \%$ CRs. The young rabbits approximated this level; however, none of the groups of older rabbits ever attained even a level of $60 \%$ CRs. Thus, asymptotic performance was not attained in the older rabbits, even in those treated with BMY 21502.

Trials to criterion. A common learning criterion reported by many researchers using the NM classical conditioning paradigm is the criterion of eight CRs in 9 consecutive trials. However, this measure is problematic when the animal does not attain learning criterion. There were 6 older ( 3 BMY 21502, 3 vehicle) and 1 younger (BMY 21502) rabbits that never attained learning criterion in 10 training sessions. Nevertheless, the sample size was sufficiently large so that there was a minimum of 9 rabbits in each cell, even when the rabbits not reaching learning criterion were eliminated. A $2 \times 2$ ANOVA comparing the effects of age and BMY 21502 on trials-to-learning criterion in the rabbits that attained criterion revealed statistically significant effects of age $[F(1,37)=28.38, p<.001]$ and treatment $[F(1,37)=6.16, p<.018]$, and a treatment $X$ age interaction $[F(1,37)=4.78, p<.03]$. The older BMY-21502-treated rabbits attained learning criterion an average of 208 trials sooner than did the older vehicle-treated rabbits (see Figure 2). Each session was 90 trials, so the older BMY-21502-treated rabbits attained criterion, on average, over two training sessions sooner than did the older vehicle-treated rabbits. The difference between the BMY-21502-treated and vehicletreated young rabbits was much smaller; on average, the vehicle-treated young rabbits attained criterion 13 trials after the BMY-21502-treated young rabbits (see Figure 2).

Unconditioned response amplitude. Amplitude of the UR is an assessment of the motor component of NM classical conditioning; it is the magnitude of the NM response to the airpuff. A $2 \times 2 \times 10$ repeated measures ANOVA comparing the effects of age, treatment dose of BMY 21502 (drug vs. vehicle), and training sessions yielded no statistically significant main effects.

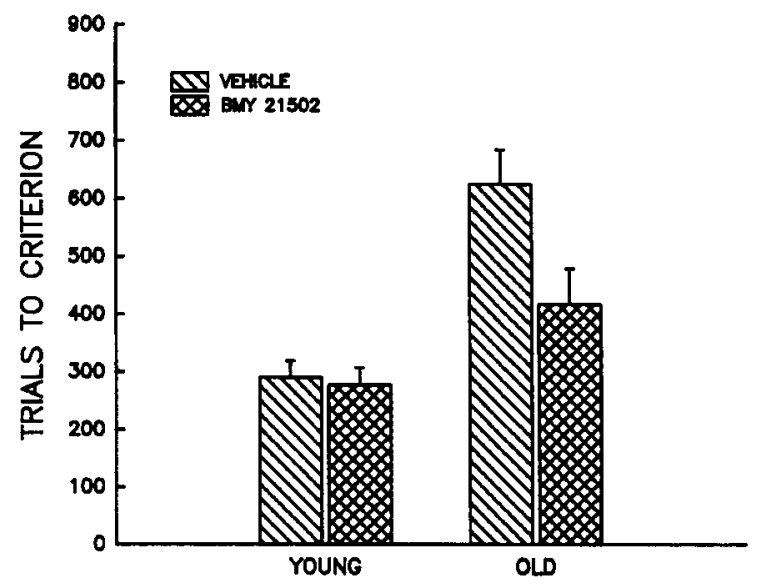

Figure 2. Trials-to-learning criterion of eight conditioned responses in nine consecutive trials in young and older rabbits. There were two treatment conditions: (1) paired tone conditioned stimulus (CS) and airpuff unconditioned stimulus after subcutaneous administration of BMY 21502 (5 and $10 \mathrm{mg} / \mathrm{kg}$ ) and (2) paired tone CS and corneal airpuff US after subcutaneous administration of vehicle.

\section{Acquisition in Older Rabbits}

Paired condition. The main hypothesis tested in this experiment was that BMY 21502 would ameliorate deficits in acquisition of CRs in older rabbits. A $2 \times 10$ repeated measures ANOVA comparing the effects of treatment dose of BMY 21502 (vehicle vs. combined 5 and $10 \mathrm{mg} / \mathrm{kg}$ ) and training sessions on percentage of CRs resulted in a statistically significant effect of training sessions $[F(9,14)=$ $13.18, p<.001]$. The main effect of treatment was not significant, but there was a significant treatment $\times$ training sessions interaction $[F(9,198)=3.02, p<.01$; Figure $3 \mathrm{~A}]$. An increase in CRs over training sessions occurred in all of the older rabbit groups, and the older rabbits treated with BMY 21502 improved to a greater extent than did the older rabbits treated with vehicle.

A $2 \times 10$ repeated measures ANOVA comparing the effects of treatment dose of BMY 21502 (vehicle vs. combined 5 and $10 \mathrm{mg} / \mathrm{kg}$ ) and training sessions on the dependent measure of CR amplitude yielded a statistically significant effect of training sessions $[F(9,198)=$ $3.63, p<.001]$. The main effect of treatment was not significant. The treatment $\times$ training sessions interaction did attain statistical significance $[F(9,198)=2.56, p<$ $.01]$. CR amplitude increased significantly in magnitude in the older rabbits over training sessions, and the older BMY-21502-treated rabbits showed greater CR amplitude increases than did the older vehicle-treated rabbits (Figure 4A).

Unpaired condition. Comparisons of performance in the explicitly unpaired condition is a control for nonspecific effects that the compound may have on the motor response (UR) or on sensitizing the animal to the CS. UR amplitude and percentage of CRs were analyzed for BMY-21502 - and vehicle-treated older rabbits in in- 

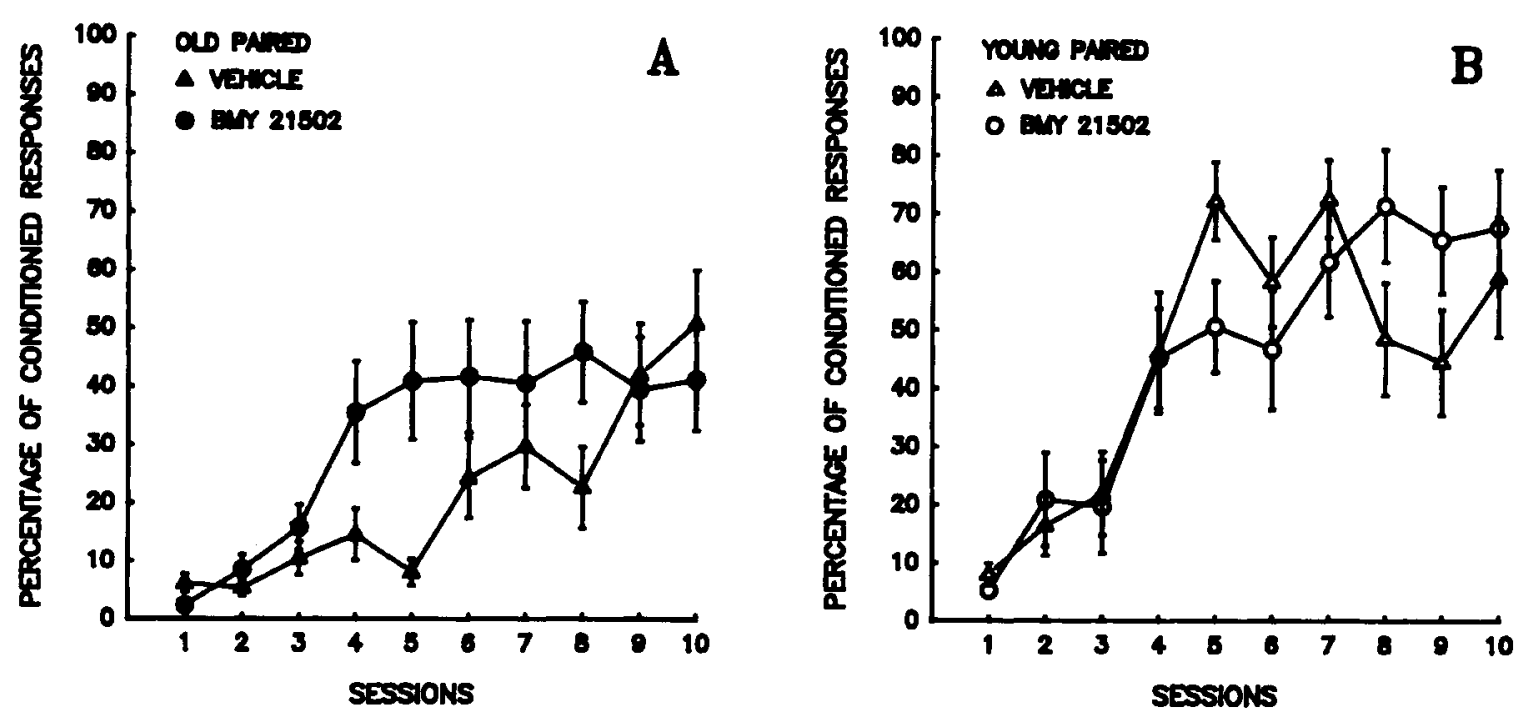

Figure 3. (A) Percentage of conditioned responses in older rabbits over 10 classical conditioning sessions of 90 tone conditioned stimulus (CS) and corneal airpuff unconditioned stimulus (US) presentations. There were two treatment conditions: (1) paired tone CS and airpuff US after subcutaneous (s.c.) administration of BMY 21502 (5 and $10 \mathrm{mg} / \mathrm{kg}$ ), and (2) paired tone CS and corneal airpuff US after s.c. administration of vehicle. There were 12 rabbits in each group. Error bars represent standard error of the mean. (B) Percentage of conditioned responses in young rabbits over 10 classical conditioning sessions of 90 tone CS and corneal airpuff US presentations. There were two treatment conditions: (1) paired tone CS and airpuff US after s.c. administration of BMY 21502 ( 5 and $10 \mathrm{mg} / \mathrm{kg}$ ), and (2) paired tone CS and corneal airpuff US after s.c. administration of vehicle. There were 12 rabbits in each group. Error bars represent standard error of the mean.
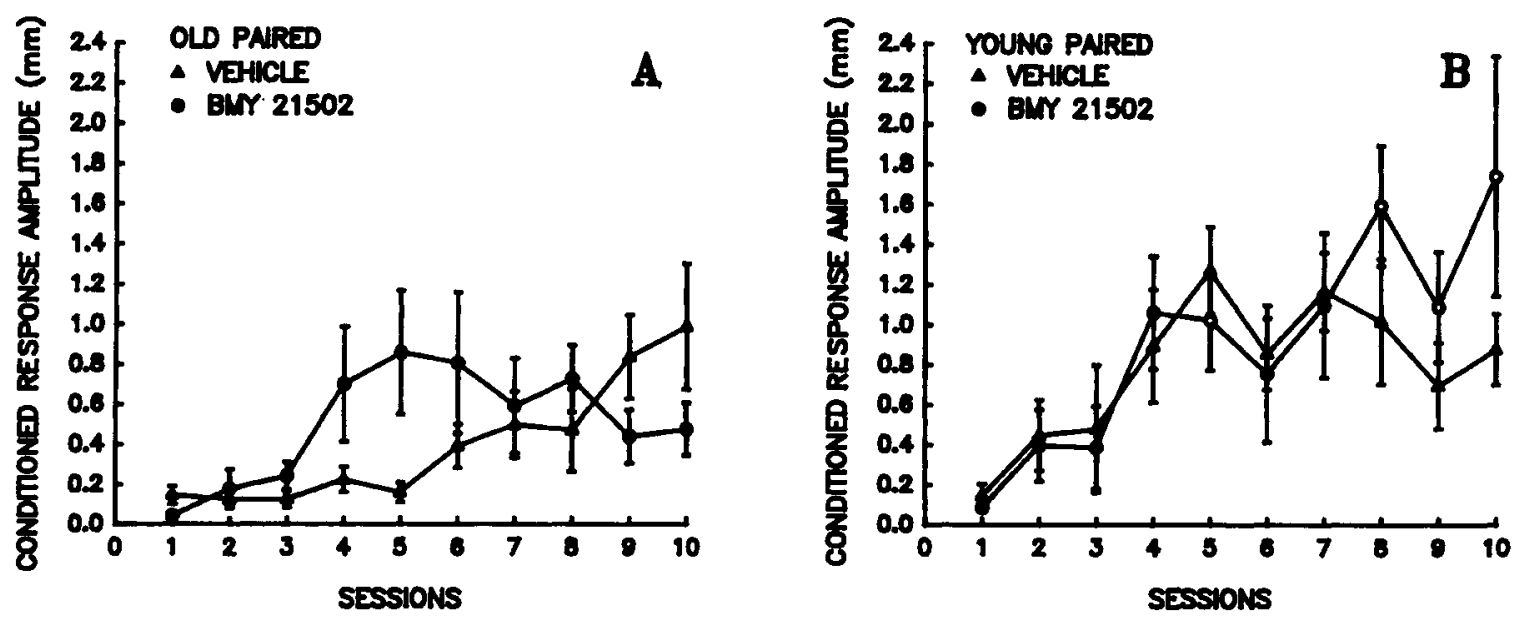

Figure 4. (A) Conditioned response amplitude in older rabbits over 10 classical conditioning sessions of 90 tone conditioned stimulus (CS) and corneal airpuff unconditioned stimulus (US) presentations. There were two treatment conditions: (1) paired tone CS and airpuff US after subcutaneous (s.c.) administration of BMY 21502 (5 and $10 \mathrm{mg} / \mathrm{kg}$ ), and (2) paired tone CS and corneal airpuff US after s.c. administration of vehicle. There were 12 rabbits in each group. Error bars represent standard error of the mean. (B) Conditioned response amplitude in young rabbits over 10 classical conditioning sessions of 90 tone CS and corneal airpuff US presentations. There were two treatment conditions: (1) paired tone CS and airpuff US after s.c. administration of BMY 21502 (5 and $10 \mathrm{mg} / \mathrm{kg}$ ), and (2) paired tone CS and corneal airpuff US after s.c. administration of vehicle. There were 12 rabbits in each group. Error bars represent standard error of the mean.

dependent $2 \times 10$ repeated measures ANOVAs comparing treatment and training sessions. None of the effects or the interaction in either the analysis of UR amplitude or percentage of CRs attained statistical significance (see Figure 5A for percentage of CRs).

\section{Acquisition in Young Rabbits}

Paired condition. A $2 \times 10$ repeated measures ANOVA comparing the effects of treatment dose of BMY 21502 (vehicle vs. combined 5 and $10 \mathrm{mg} / \mathrm{kg}$ ) and training sessions on the percentage of CRs in the young rabbits yielded 

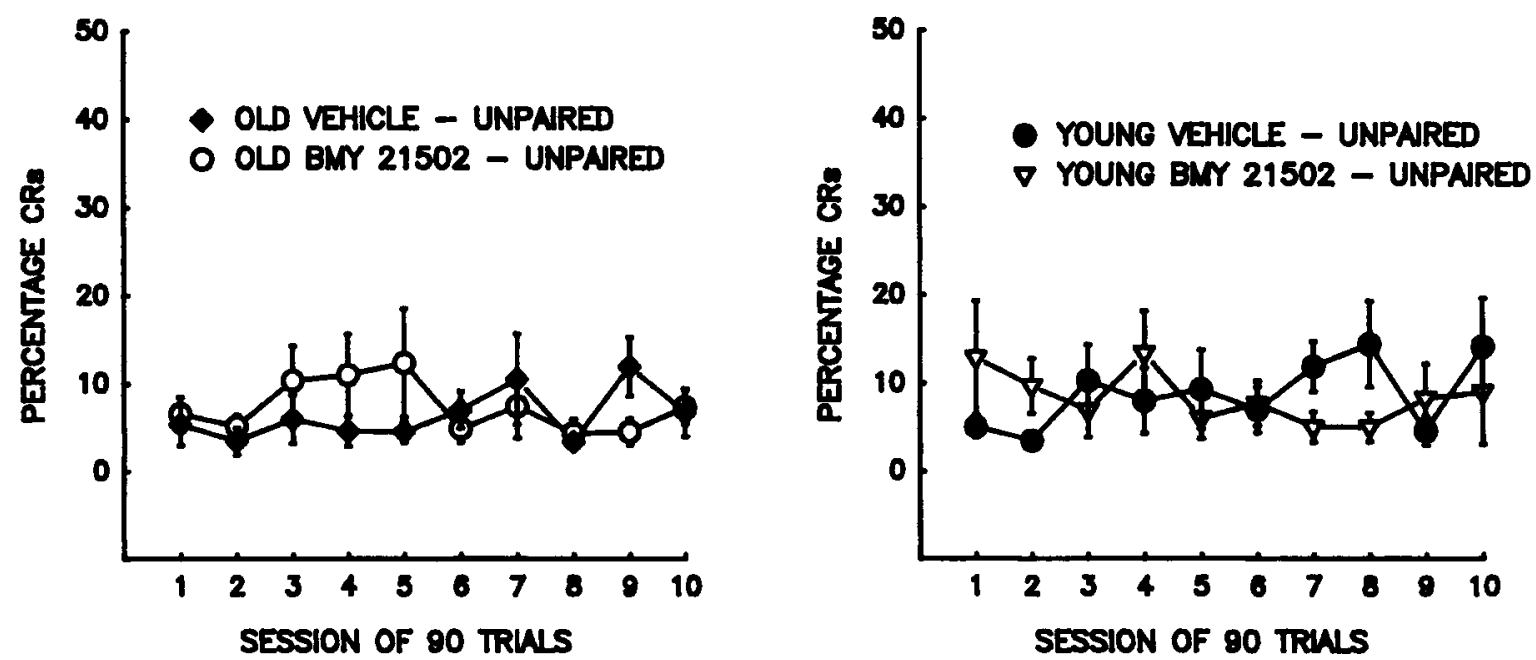

Figure 5. Left panel: Percentage of conditioned responses (CRs) in older rabbits over 10 classical conditioning sessions of 180 explicitly unpaired presentations of tone and corneal airpuff. There were two treatment conditions: (1) unpaired presentations and $5 \mathrm{mg} / \mathrm{kg}$ of BMY $21502(N=6)$, and (2) unpaired presentations and vehicle $(N=8)$. Error bars represent standard error of the mean. Right panel: Percentage of CRs in young rabbits over 10 classical conditioning sessions of 180 explicitly unpaired presentations of tone and corneal airpuff. There were two treatment conditions: (1) unpaired presentations and $5 \mathrm{mg} / \mathrm{kg}$ of BMY $21502(N=6)$, and (2) unpaired presentations and vehicle $(N=8)$. Error bars represent standard error of the mean.

a significant effect of training session $[F(9,198)=18.34$, $p<.001$; Figure 3B]. The main effect of treatment and the treatment $\times$ training sessions interaction did not attain statistical significance. An increase in percentage of CRs occurred in all the groups of young rabbits, and it was similar whether the animals were treated with BMY 21502 or vehicle.

A $2 \times 10$ repeated measures ANOVA comparing the effects of treatment dose of BMY 21502 (vehicle vs. combined 5 and $10 \mathrm{mg} / \mathrm{kg}$ ) and training sessions on the dependent measure of CR amplitude yielded a significant effect of training sessions $[F(9,198)=5.58, p<.001]$. The main effect of treatment and the treatment $X$ training sessions interaction did not attain statistical significance. CR amplitude increased in magnitude over training sessions for all the groups of young rabbits (Figure 4B).

Unpaired condition. The percentage of CRs and UR amplitude were analyzed for BMY-21502- and vehicletreated young rabbits in independent $2 \times 10$ repeated measures ANOVAs comparing treatment and training session. None of the main effects or the interaction were significant in the analysis of percentage of CRs (see Figure 5B). The effect of treatment on UR amplitude was significant $[F(1,12)=10.80, p<.01]$, but the effect of training sessions and the treatment $\times$ training sessions interaction did not attain statistical significance. UR amplitude was significantly larger in the young vehicle-treated rabbits, but there was no effect on percentage of CRs.

\section{DISCUSSION}

There were significant age differences in the acquisition of the classically conditioned NM response in the rabbits, and the young rabbits attained higher asymptotic performance levels. When the effect of BMY 21502 was examined in the overall analysis of percentage of CRs with the young and old rabbits, the compound's effect did not attain statistical significance. The young rabbits treated with BMY 21502 did not condition better than the vehicle-treated young rabbits. When we compared the groups of older rabbits among themselves, it was apparent that, over training sessions, the BMY-21502treated older rabbits produced an overall higher percentage of CRs and produced higher amplitude CRs earlier in training than did the vehicle-treated older rabbits. However, the older rabbits treated with BMY 21502 did not attain higher asymptotic levels of performance than the vehicle-treated older rabbits.

In both the vehicle-treated and the BMY-21502treated young rabbits, learning criterion was achieved, on average, during Day 4 of training. On average, the BMY-21502-treated older rabbits attained learning criterion on Day 5 of training, whereas the vehicle-treated older rabbits attained learning criterion, on average, on Day 7 of training. The interaction between trials to criterion in the BMY-21502- and vehicle-treated younger and older rabbits attained statistical significance, indicating that the compound ameliorated learning deficits in the older group.

Amplitude of the UR was significantly greater in the young vehicle-treated rabbits in the unpaired condition than it was in the young BMY-21502- treated rabbits in the unpaired condition. This result is difficult to explain, given that in the paired groups there was not a significant difference between UR amplitude in the vehicle-treated versus the BMY-21502-treated rabbits. The unpaired 
vehicle-treated rabbits were run over a year after the other groups, when it was determined that the unpaired vehicle condition was an essential control for this experiment. Since UR amplitude was not different in the rabbits that were run initially, it is possible that the higher UR amplitude in the unpaired young vehicle group that was run later occurred as a consequence of different animal trainers, individual variations in rabbits, and/or slight differences in calibration of the equipment over that period of time. Because there was no consistent difference in UR amplitude between the BMY-21502- and vehicle-treated rabbits in the paired and unpaired groups, it is unlikely that BMY 21502 affected acquisition by enhancing the reflexive motor response.

UR amplitude differences in the unpaired condition occurred between the groups of BMY-21502- and vehicletreated young rabbits. However, BMY 21502 did not have a significant effect on CR percentage, CR amplitude, response latency, or trials to criterion in the young rabbits. In the older rabbits, there was a higher percentage of CRs and greater CR amplitude earlier in training in the BMY-21502-treated than in the vehicle-treated groups. UR amplitude was not significantly different in the older unpaired BMY-21502- and vehicle-treated rabbits. In the older rabbits, BMY 21502 ameliorated deficits in acquisition as assessed by CR percentage and CR amplitude, but the compound did not significantly affect the motor component of the response, UR amplitude.

The results reported here are behavioral, and neural activity was not monitored during acquisition in this experiment. Previous research on the model system of NM classical conditioning in rabbits has demonstrated that two brain structures are engaged. The hippocampus plays a modulatory role in acquisition, and the ipsilateral cerebellum is essential for acquisition and retention (Thompson, 1986, 1990). It is possible that the mechanism of action of BMY 21502 on NM conditioning was mediated through one of these two brain structures. With the present data, we cannot determine the site of action of BMY 21502 and the mechanism by which it ameliorates deficits in acquisition in older rabbits. Nevertheless, because the neural circuitry in the model system of $\mathrm{NM}$ /eyeblink classical conditioning in the rabbit is well understood, there are clear directions for future research.

\section{REFERENCES}

Braun, H. W., \& Geiselhart, R. (1959). Age differences in the acquisition and extinction of the conditioned eyelid response. Journal of Experimental Psychology, 57, 386-388.

Coffin, J. M., \& WoOdRUfF-PAK, D. S. (1993). Delay classical conditioning in young and older rabbits: Initial acquisition and retention at 12 and 18 months. Behavioral Neuroscience, 107, 61-72.

Fitten, L. J., Perryman, K. M., Hanna, J. A., \& Menon, M. K. (1990). Effect of BMY 21502 on acquisition of shape discrimination and memory retention in monkey. Pharmacology, Biochemistry \& Behavior, 35, 553-556.

GIURGIA, C. (1976). Nootropic pharmacology of neurointegrative activity. Current Reviews of Psychopharmacology, 3, 221-276.

Graves, C. A., \& Solomon, P. R. (1985). Age related disruption of trace but not delay classical conditioning of the rabbit's nictitating membrane response. Behavioral Neuroscience, 99, 88-96.

Gribkoff, V. K., Bauman, L. A., \& VanderMaelen, C. P. (1990). A 1-heteroaryl-4-piperidinyl-methyl pyrrolidinone, BMY 21502, delays the decay of hippocampal synaptic potentiation in vitro. Neuropharmacology, 29, 1001-1009.

Gribkoff, V. K., Eison, M. S., Moon, S. L., Martin, T. L., Taylor, D. P., VanderMaelen, C. P., Mattson, R. J., \& YocCa, F. D. (1989). The behavioral effects and cellular actions of a new potential cognition enhancement agent, BMY 21502. In R. J. Wurtman S. Corkin, J. H. Growdon, \& E. Ritter-Walker (Eds.), Alzheimer's disease: Advances in basic research and therapy (pp. 709-714). Cambridge, MA: Center for Brain Sciences and Metabolism Charitable Trust.

Harrison, J., \& BuchWALD, J. (1983). Eyeblink conditioning deficits in the old cat. Neurobiology of Aging, 4, 45-51.

HaRveY, J. A., \& Gormezano, I. (1986). The assessment of drug effects on learning and stimulus processing by means of classical conditioning. In T. Thompson \& N. A. Krasnegor (Eds.), Developmental behavioral pharmacology (pp. 115-132). Hillsdale, NJ: Erlbaum.

Kimble, G. A., \& Pennypacker, H. S. (1963). Eyelid conditioning in young and aged subjects. Journal of Genetic Psychology, 103, 283289.

LINDER, M. D., \& GRIBKOFF, V. K. (1992). Effects of oral BMY 21502 on Morris water task performance in 16-18 month old F-344 rats. Psychopharmacology, 107, 485-488.

MCCoRmick, D. A., LAVOND, D. G., \& THompson, R. F. (1982). Concomitant classical conditioning of the rabbit nictitating membrane and eyelid responses: Correlations and implications. Physiology \& Behavior, 28, 769-775

MoON, S. L., Matrson, R. J., Yocca, F. D., Taylor, D. P., Yevich, J. P., EISON, M. S., RIBLET, L. A., \& TEMPLE, D. L. (1988). BMY 21502: A potential cognition enhancer that improves memory and enhances glucose metabolism in aged hippocampus. Society for Neuroscience Abstracts, 14, 207.

OLPE, H.-R., \& LYNCH, G. S. (1982). The action of piracetam on the electrical activity of the hippocampal slice preparation: A field potential analysis. European Journal of Pharmacology, 80, 415-419.

Pierce, J. E. S., Smith, D. H., EIson, M. S., \& McIntosh, T. K. (1993). The nootropic compound BMY-21502 improves spatial learning ability in brain injured rats. Brain Research, 624, 199-208.

Powell, D. A., Buchanan, S. L., \& Hernandez, L. L. (1981). Age related changes in classical (Pavlovian) conditioning in the New Zealand albino rabbit. Experimental Aging Research, 7, 453-465.

Sasse, D. K., Coffin, J. M., \& Woodruff-PaK, D. S. (1991). Age differences in rabbits in the delay classical conditioning paradigm using 400 and $750 \mathrm{~ms}$ CS-US intervals. Society for Neuroscience Abstracts, 17, 1140.

SASSE, D. K., \& WoOdrufF-PAK, D. S. (1990). Classical conditioning in young and older rabbits in delay and trace paradigms with a $750 \mathrm{msec}$ CS-US interval. Society for Neuroscience Abstracts, 16, 841.

SATOH, M., IshihaRa, K., IWAMa, T., \& TAKaGi, H. (1986). Aniracetam augments, and midazolam inhibits, the long-term potentiation in guinea pig hippocampal slices. Neuroscience Letters, 68, 216-220.

Schindler, C. W., Gormezano, I., \& Harvey, J. A. (1984). Sensory and associative effects of morphine and naloxone in classical conditioning of the rabbit nictitating membrane response. Psychopharmacology, 83, 114-121.

Solomon, P. R., Pomerleau, D., Bennett, L., James, J., \& Morse, D. L. (1989). Acquisition of the classically conditioned eyeblink response in humans over the life span. Psychology \& Aging, 4, 34-41.

Thompson, R. F. (1986). The neurobiology of learning and memory. Science, 233, 941-947.

THOMPSON, R. F. (1990). Neural mechanisms of classical conditioning in mammals. Philosophical Transactions of the Royal Society of London, 319, 161-170.

Thompson, R. F., Berger, T. W., Cegavske, C. F., Patterson, M. M., ROEMER, R. A., TEYLER, T. J., \& YOUNG, R. A. (1976). A search for the engram. American Psychologist, 31, 209-227. 
Weiss, C., \& Thompson, R. F. (1991). The effects of age on eyeblink conditioning in the freely moving Fischer-344 rat. Neurobiology of Aging, 12, 249-254.

WoODRUFF-PAK, D. S. (1990). Mammalian models of learning, memory, and aging. In J. E. Birren \& K. W. Schaie (Eds.), Handbook of the psychology of aging (3rd ed., pp. 235-257). New York: Academic Press.

Woodruff-PaK, D. S., Coffin, J. M., \& SAsSe, D. K. (1991). Learning, memory, and aging: Neural changes and drug actions. In K. W. Schaie (Ed.), Annual review of geriatrics and gerontology (Vol. 11, pp. 23-54). New York: Springer-Verlag.
Woodruff-PaK, D. S., Lavond, D. G., Logan, C. G., \& Thompson, R. F. (1987). Classical conditioning in 3-, 30-, and 45-month-old rabbits: Behavior and hippocampal unit activity. Neurobiology of Aging, 8, 101-108.

WoOdRufF-PAK, D. S., \& Thompson, R. F. (1988). Classical conditioning of the eyeblink response in the delay paradigm in adults aged 18-83 years. Psychology \& Aging, 3, 219-229.

(Manuscript received August 17, 1992;

revision accepted for publication August 17, 1994.) 